\section{Mitigate damage risk from bush fires}

As climate models project a severely increased fire risk in southeastern Australia (H. G. Clarke et al. Int. J. Wildland Fire 20, 550-562; 2011), we urgently need to put a stop to social processes that are amplifying our risk from bush fires (R. P. Crompton et al. Wea. Climate Soc. 2, 300-310; 2010). More thoughtful land use and planning could curb the destruction they cause in and around cities.

Interviews with residents following the recent fires in Sydney echoed those after the devastating Black Saturday bush fires in the state of Victoria in 2009 (J. Whittaker et al. Int. J. Wildland Fire 22, 841-849; 2013). These residents likewise complained that government restrictions prevented them from clearing trees on their land as a fire break and that suburbia continues to expand into untamed bush land without due preparedness and protection.

The recent blazes in Sydney occurred earlier in the fire season than usual, prompting speculation about a possible link with climate change.

Katharine Haynes, Deanne Bird, John McAneney Risk Frontiers, Macquarie University, Sydney, Australia.

haynes.katharine@gmail.com

\section{Russian universities need change of tack}

Of the factors contributing to Russia's poor scientific performance (see, for example, A. Gorobets Nature 503, 39; 2013), the plight of the country's university professors stands out.

These professors are poorly paid; most are forced to supplement their earnings with other employment. Their typical annual teaching load of up to 1,000 hours is three to five times higher than that in universities elsewhere, leaving them little time for research or writing up their work. On top of this, professors are now under pressure from Russia's Ministry of Education and Science to publish two or three papers a year in international journals to help their universities to reach the top 200 in global rankings.

By contrast, the world's leading universities do not expect their professors to teach for more than 200-400 hours a year, allowing them enough time for research. They also protect the intellectual property that results from this research, which contributes substantially to university budgets - amounting in some US universities to several billions of dollars a year (roughly the combined research budget for some provinces and republics in the Russian Federation).

A transfer to universities of institutions currently owned by the beleaguered Russian Academy of Sciences (see Nature http://doi.org/p6d) might offer a solution. It would empower university research, help to dissolve Russia's rigid and detrimental educationresearch divide, and ultimately boost the rankings of Russian universities.

Renad Zhdanov Kazan Federal University, Russia, and Sholokhov Moscow State University for the Humanities, Moscow, Russia. zrenad@gmail.com

\section{Definition of maths genius is elusive}

'Project Einstein' aims to identify the genotypes of prominent mathematicians (Nature 502, 602-603; 2013), but it needs to be underpinned by an accurate definition of the mathematicalgenius phenotype.

Basic mathematical competence is judged according to numeracy and arithmetical skills. Advanced ability is less easily delineated; genius-level mathematical ability is even harder to define. Advanced mathematics encompasses diverse elements such as sophisticated abstract thought, statistical know-how, raw computation, geometric awareness, imagination, lateral thinking, logic and philosophy. Moreover, proficiency in all of these areas has yet to be properly quantified in terms of inherent versus learned ability.

So the genetic heterogeneity studied through gene sequencing is unlikely to arrive at a 'mathematicalgenius genome'. Such studies may, however, shed light on frequently associated neurodevelopmental conditions (see, for example, S. BaronCohen et al. J. Autism Dev. Disord. 31, 5-17; 2001).

Hutan Ashrafian Imperial College London, UK. h.ashrafian@imperial.ac.uk

\section{Greece's high CT scanning record}

You remark on the high number of computed tomography (CT) scans used in Greece, but only risk-benefit analysis and cost-effectiveness studies will indicate whether this is a good or a bad thing (Nature 502, S82S83; 2013). Your claim that the country has no official guidelines governing the use of CT scans is not correct.

CT scanners in Greece have been regularly monitored under strict guidelines since 2001 . And diagnostic and therapeutic protocols in radiology were implemented in 2011.

Peculiarities in Greece's health system contribute to the high level of CT scanner use. The number of doctors per capita is almost double the average for countries in the Organisation for Economic Co-operation and Development, which may result in overprescription of diagnostic procedures. This could be due in part to the relatively low cost of CT scans in Greece (US $\$ 88$ for a chest scan, for example, compared with $\$ 332$ in the United States). A new electronic referral system has now been set up that should discourage overprescribing.

Ioannis Seimenis University of Thrace, Greece.

Stelios Argentos, Stathis Efstathopoulos University of Athens, Greece. stathise@med.uoa.gr

\section{TB vaccine failure was predictable}

Your report on tuberculosis (TB) vaccines perpetuates a flawed but widely held view. In fact, the lack of efficacy of the MVA85A vaccine in a recent human clinical trial was no surprise (Nature 502, S8-S9; 2013).

The trial followed an immunization regime previously used in four animal models in the past ten years. Careful examination of those results reveals that MVA85A offered no statistically significant increase in protection over the $\mathrm{BCG}$ (Bacillus Calmette-Guérin) vaccine alone in mice, guinea pigs, cows and non-human primates (see, for example, F. A. W. Verreck et al. PLoS ONE 4, e5264; 2009, and S. A. Sharpe et al. Clin. Vaccine Immunol. 17, 1170-1182; 2010).

The only exception is a mouse study (N. P. Goonetilleke et al. J. Immunol. 171, 1602$1609 ; 2003)$, which is not comparable because a different immunization route was used (see C. N. Horvath and Z. Xing Adv. Exp. Med. Biol. 783, 267-278; 2013).

In aggregate, therefore, the preclinical animal data for MVA85A predicted the outcome of the reported clinical trial. It remains to be seen how successfully animal models will predict the efficacy of other TB vaccine candidates.

Peter Beverley University of Oxford, UK.

peter.beverley@ndm.ox.ac.uk 